\title{
ОГРАНИЧЕНИЕ ТОЧНОСТИ ИЗМЕРЕНИЯ ТЕМПЕРАТУРЫ ПОЛУПРОВОДНИКОВЫМИ ДАТЧИКАМИ В ЗАВИСИМОСТИ ОТ КОЭФФИЦИЕНТА СТАБИЛИЗАЦИИ РАБОЧЕГО ТОКА
}

\author{
О.А. Абдулхаев, Р.Р. Бебитов, А.Р. Абдулхаева, Д.М. Ёдгорова \\ Физико-технический институт АН РУз 100084, Ташкент, ул. Чингиз Айтматов, 2б, \\ Узбекистан, abdulhaev@uzsci.net \\ (Получена 23.07.2018)
}

\begin{abstract}
Яримўтказгичли датчиклар хєарорат ўлчаш аникฺлигининг ишчи токининг стабиллиги коэффициентига боғлиқ़лигини тадқฺиқоти натижалари келтирилган. Вольтампер таснифида кุияликнинг мавжудлиги хчамда ушбу қчиялик көйматини температурага боғликелиги ишчи токининг стабиллик коэффициенти, ишчи токи қиймати ва хчароратни ўлчаш сохєасига боғлиқ хєолда хุароратни ўлчаш аникчлигига чеклов қў̆̆иши кўрсатилган.
\end{abstract}

\begin{abstract}
Представлены результаты исследования зависимости точности измерения температуры полупроводниковыми датчиками от коэффициента стабилизации рабочего тока. Показано, что наличие наклона вольтамперной характеристики, а также её зависимость от температуры накладывают ограничения на точность измерения в зависимости от коэффициента стабилизации рабочего тока, значений рабочего тока и области измеряемой температуры.
\end{abstract}

The dependence of accuracy of temperature measurement by semiconductor sensors on stabilization factor of the current source is investigated and the results are presented. It is shown that the presence of slope of the current-voltage characteristic, as well as its dependence on temperature, impose limitations on the measurement of accuracy depending on the stabi;ization factor of the current source, the value of the operating current and the region of the measured temperature.

Введение. Развитие приборостроения в области медицины и улучшение обеспеченности населения и медицинских учреждений доступными, качественными изделиями медицинского назначения, реализация мер по недопущению необоснованного роста цен на них являются одним из важных задач. В частности, измерение температуры тела, являясь одной из важных процедур в медицине, позволяет своевременно оценивать состояние организма и принимать меры по выявлению причины недуга и лечению болезни $[1,2]$. Кроме того, измерения температуры широко применяются в хирургии в качестве средства контроля, в медицинской диагностике и в терапии. При этом температура является регулирующим терапевтическую процедуру показателем, своего рода обратной связью с биологическим объектом.

В настоящее время в Узбекистане используются в основном термометры, состоящие из помещенной в стеклянный корпус ртути, которая пропорционально воздействующей температуре меняет объем. Они, требуя длительное время для регистрации температуры тела, являются также токсичными и небезопасными, особенно при использовании для измерения температуры тела детей. При этом, как отмечено в «Минаматской конвенции о ртути» [3], начиная с 2020 года, прекращаются производство, экспорт и импорт изделий, содержащих ртуть, в их числе все типы термометров, содержащие ртуть. В связи с чем запрос на другие виды термометров будет очень востребованным. Однако в настоящее время в 
Узбекистане отсутствует производство термометров и термодатчиков, и вся потребность отраслей республики удовлетворяется за счет импорта.

В разрабатываемых электронных термометрах для измерения температуры тела используются термодиоды, термотранзисторы, резисторные и интегральные термодатчики $[4,5]$. В том числе в Узбекистане ведутся работы по разработке термодатчиков в виде кремниевых терморезисторов с компенсированной базовой областью: с применением диффузионной технологии путем легирования примесями переходных металлов (марганец, никель и др.) [6] и путем терморадиационного легирования кремния [7]. Кроме того, на основе интегральных схем на комплементарных транзисторах, состоящих из нескольких десятков транзисторов, предложен ряд термодатчиков, способных осуществлять мониторинг температуры различных объектов [8, 9], в частности, выпускающиеся АО «FOTON» микросхемы K1019EM1, представляющие собой термочувствительный элемент с линейной зависимостью выходного напряжения от температуры и содержащие 28 интегральных элементов.

Общим недостатком известных полупроводниковых датчиков является их низкая точность измерения температуры. Точность измерения температуры в полупроводниковых датчиках определяется совокупностью множества факторов, большинство которых является следствием неидеальной воспроизводимости технологического производства полупроводниковых приборов, приводящего к отклонению характеристик датчиков от стандартной кривой. Например, несоответствие коэффициента неидеальности или последовательного сопротивления используемого датчика соответствующим параметрам ранее калиброванного датчика приводит к существенному снижению точности измерения.

Настоящая работа посвящена определению зависимости точности измерения температуры полупроводниковыми датчиками от коэффициента стабилизации рабочего тока.

Исследуемые образцы. Для исследования были изготовлены кремниевые $p$ - $n$ структуры, состоящие из эпитаксиального слоя $n$-типа с концентрацией носителей $5 \times 10^{15} \mathrm{~cm}^{-3}$ и толщиной 3.5-3.88 мкм, выращенного на подложке кремния $p^{+}$-типа с концентрацией носителей $3 \times 10^{16} \mathrm{~cm}^{-3}$ и толщиной 380 мкм. На части поверхности эпитаксиального слоя диффузией бора сформирована дополнительная сильнолегированная область $p^{++}$-типа толщиной 0.9-1.4 мкм и с концентрацией носителей $3 \times 10^{18} \mathrm{~cm}^{-3}$, которая технологически закорочена с подложкой $p^{+}$-типа. В результате в готовой структуре сформированы два выпрямляющих перехода, один с $n-p^{++}$-переходом, а другой с $p^{+}-n$-переходом, которые параллельно соединены между собой. Контакты к этим областям сформированы напылением слоя $\mathrm{Al}$

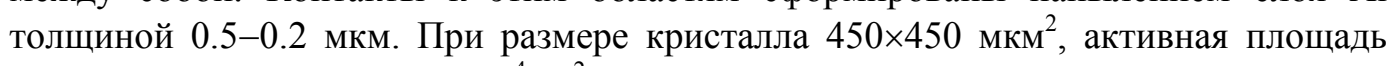
структуры составляет $2.36 \times 10^{-4} \mathrm{~cm}^{2}$.

Методика исследования. Вольтамперные характеристики снимали по стандартной схеме. Рабочее напряжение подавали от блока питания типа Б5-48 и Б5-50 с шагом 0.05 В. Напряжение фиксировали универсальным вольтметром Щ301. Минимальный измеренный ток был равен 0.1 нА, которую измеряли на В730 и Щ300. Температурные исследования проводили с использованием специального криостата, в котором в качестве хладагента был использован жидкий азот, а температурный режим задавали с помощью нагревателя, вмонтированного в 
держатель образца, помещаемого внутри измерительной камеры. Задаваемую температуру от $-180^{\circ} \mathrm{C}$ до $150^{\circ} \mathrm{C}$ измеряли термопарой хромель-алюмель и поддерживали терморегулятором 2ТРМ1.

Полученные результаты и их обсуждение. Измерены вольтамперные характеристики изготовленных $p$ - $n$-структур в режиме прямого смещения при различных температурах, а также вольт-температурные характеристики при различных рабочих токах, которые представлены на рис. 1 и 2 соответственно.

Наблюдаемое изменение показателя коэффициента неидеальности с повышением температуры можно объяснить переходом механизма токопереноса с рекомбинационного на диффузионный. Поскольку диффузионный ток, в отличие от рекомбинационного, пропорционален квадрату собственной концентрации, то с ростом температуры по мере увеличения собственной концентрации начинает

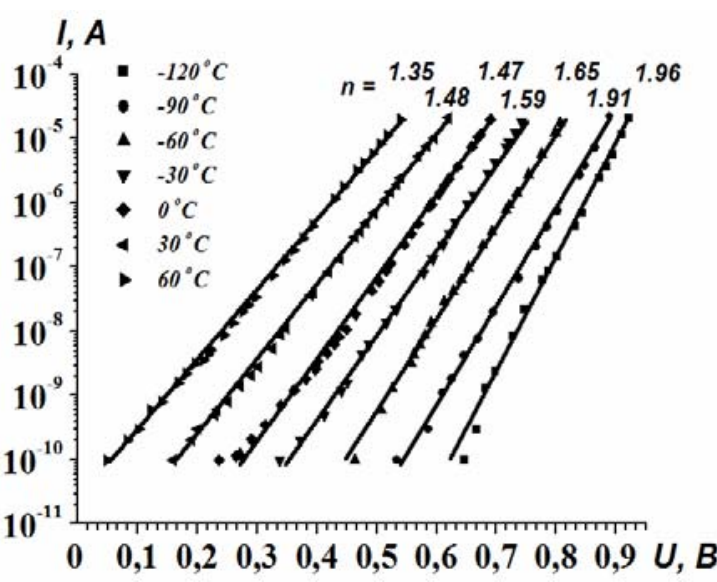

Рис. 1. Зависимость тока от напряжения прямосмещеннего $p$ - $n$-перехода при различных температурах в полулогарифмическом масштабе.

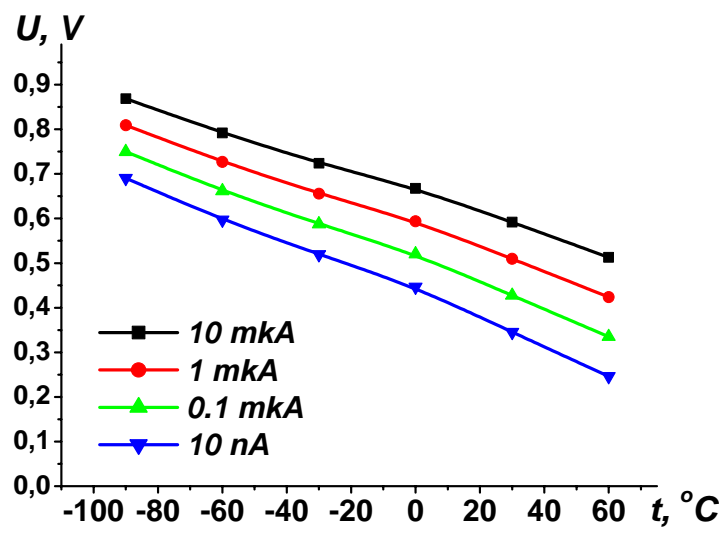

Рис. 2. Вольт-температурная характеристика прямосмещеннего $p$ - $n$-перехода при различных рабочих токах превалировать диффузионный ток, что и приводит к наблюдаемому на эксперименте изменению коэффициента неидеальности. Наличие наклона вольтамперной характеристики приводит к тому, что регистрируемое изменение прямого падения напряжения может быть следствием не только изменения температуры, но также и изменения значения рабочего тока. Вследствие этого накладывается ограничение на точность измерения температуры в зависимости от коэффициента стабилизации рабочего тока, а изменение наклона токовой характеристики c температурой еще больше затрудняет точное измерение температуры. Исследования вольт-температурной зависимости показывают, что температурный коэффициент чувствительности имеет нарастающий характер со снижением рабочего тока (рис. 2). Однако для обеспечения линейной зависимости напряжения от температуры рабочий ток необходимо выбрать несколько больше (не менее чем на порядок) тока насыщения. 
Определенные из экспериментальных кривых вольтамперной и вольттемпературной характеристик ограничения, накладываемые на точность измерения температуры в зависимости от значений рабочего тока и температуры при различных коэффициентах стабилизации рабочего тока, представлены в таблице. Видно, что при неизменном коэффициенте стабилизации рабочего тока погрешность определения температуры по мере снижения рабочего тока уменьшается, а при повышении температуры увеличивается.

Таблица. Ограничение точности измерения температуры в зависимости от значения рабочего тока и температуры при различных коэффициентах стабилизации рабочего тока.

\begin{tabular}{l|c|c|c|c|c|c|c}
\hline \multirow{2}{*}{ Ток } & \multicolumn{7}{c}{ Коэффициент стабилизации рабочего тока $\Delta I / I=0.01$} \\
\cline { 2 - 8 } & $-120^{\circ} \mathrm{C}$ & $-90^{\circ} \mathrm{C}$ & $-60^{\circ} \mathrm{C}$ & $-30^{\circ} \mathrm{C}$ & $0^{\circ} \mathrm{C}$ & $30^{\circ} \mathrm{C}$ & $60^{\circ} \mathrm{C}$ \\
\hline \multirow{2}{*}{10 мкА } & \pm 0.102 & \pm 0.111 & \pm 0.121 & \pm 0.127 & \pm 0.137 & \pm 0.153 & \pm 0.165 \\
1 мкА & \pm 0.094 & \pm 0.102 & \pm 0.112 & \pm 0.117 & \pm 0.127 & \pm 0.152 & \pm 0.153 \\
0.1 мкА & \pm 0.087 & \pm 0.095 & \pm 0.103 & \pm 0.109 & \pm 0.117 & \pm 0.131 & \pm 0.142 \\
\hline \multirow{7}{*}{ Ток } & \multicolumn{7}{c}{ Коэффициент стабилизации рабочего тока $\Delta I / I=0.001$} \\
\cline { 2 - 8 } & $-120^{\circ} \mathrm{C}$ & $-90^{\circ} \mathrm{C}$ & $-60^{\circ} \mathrm{C}$ & $-30^{\circ} \mathrm{C}$ & $0^{\circ} \mathrm{C}$ & $30^{\circ} \mathrm{C}$ & $60^{\circ} \mathrm{C}$ \\
\hline 10 мкA & \pm 0.010 & \pm 0.011 & \pm 0.012 & \pm 0.013 & \pm 0.014 & \pm 0.015 & \pm 0.017 \\
1 мкА & \pm 0.009 & \pm 0.010 & \pm 0.011 & \pm 0.012 & \pm 0.013 & \pm 0.014 & \pm 0.015 \\
0.1 мкА & \pm 0.009 & \pm 0.009 & \pm 0.010 & \pm 0.011 & \pm 0.012 & \pm 0.013 & \pm 0.014 \\
\hline
\end{tabular}

При высокой степени стабилизации рабочего тока точность измерения определяется технологическим разбросом параметров от одного образца к другому. В частности, на рис. 3 представлены вольт-температурные характеристики в режиме прямого смещения $p$ - $n$-перехода для пяти образцов из одной технологической серии, которые указывают на то, что даже при незначительном изменении коэффициента неидеальности наблюдается значительное отклонение от стандартной калибровочной кривой.

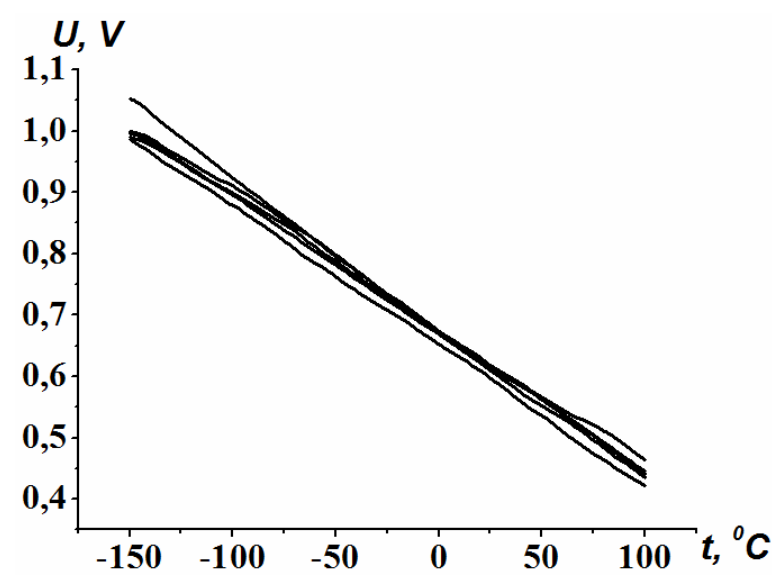

Рис. 3. Вольт-температурные характеристики в режиме прямого смещения $p$ - $n$-перехода для пяти образцов из одной технологической серии

Заключение. Таким образом, показано, что наличие наклона вольтамперной характеристики, а также её зависимость от температуры накладывают ограничения на точность измерения в зависимости от коэффициента стабилизации рабочего тока, значения рабочего тока и области измеряемой температуры. Следовательно, для достижения высоких значений заявленных точностей измерения в известных датчиках температуры требуется их питание от источников тока с высокой степенью стабилизации рабочего тока. Данное свойство является общим 
недостатком всех известных полупроводниковых датчиков: резисторных, диодных и транзисторных.

Для создания датчика температуры без указанных недостатков нами ранее предложена новая структура и конструкция термодатчика [10], которая представляет собой структуру с двухуровневыми двумя контактными областями в базовой области одного типа, сформированных в сильнолегированной области другого типа проводимости. Рабочим является обратное напряжение, прилагаемое к контакту, находящемуся на верхнем уровне, и к контакту к сильнолегированной области. Измерительный потенциал снимается с находящегося на нижнем уровне контакта к базе. При определенном запирающем рабочем напряжении (отсечке) происходит полное обеднение со стороны нижнего уровня базы, а измерительный потенциал (напряжение) от нарастающего рабочего напряжения приобретает неизменное значение, но при повышении температуры будет возрастать пропорционально ей. Отношение приращения измерительного потенциала к приросту температуры представляет собой температурный коэффициент термочувствительности, который не зависит от рабочего напряжения или тока, то есть обладает самостабилизируемым характером.

\section{ЛИТЕРАТУРА}

1. P. Keikhosrokiani, et al. In: Mobile Health. Eds. S. Adibi (Springer, 2015), pp. 687-726.

2. A.S. El-Radhi, W. Barry, Archives of disease in childhood. 91, 351 (2006).

3. www.mercuryconvention.org.

4. P.R.N. Childs, J.R. Greenwood, C.A. Long, Review of Scientific Instruments 71, 2959 (2000).

5. M. Mansoora, I. Haneefa, S. Akhtara, A. De Lucac, F. Udrea, Sensors and Actuators A: Physical 232, 63 (2015).

6. M.K. Bakhadyrkhanov, S.A. Valiev, S.A. Tachilin, S.S. Nasriddinov, Surface Engineering and Applied Electrochemistry 43 (6), 505 (2007).

7. M. Karimov, Sh. Makhkamov, Sh.A. Makhmudov, R.A. Muminov, A.Z. Rakhmatov, L.S. Sandler, A.R. Sattiev, A.A. Sulaimanov, N.A. Tursunov, Applied Solar Energy 46 (4), 298 (2010).

8. F. Udrea, S. Santra, J.W.Gardner. In: Proceedings of International Semiconductor Conference (Sinaia, Romania, 13-15 October, 2008). PP. 31-40.

9. K. Souri, Y. Chae, K.A.A. Makinwa, IEEE Journal of Solid-State Circuits 48 (1), 292 (2013).

10. А.В. Каримов, Д.М. Ёдгорова, О.А. Абдулхаев, Д.Р.Джураев, А.А Тураев. Патент РУз № IАР 05120, Бюл. № 11 от 30.11.2015. 